\section{Liberal colleges ask for more}

\section{Washington}

EMPHASIZING their "significant and increasingly important contribution to America's scientific manpower pool", a group of fifty leading US liberal arts colleges say they will need to spend an additional $\$ 1,000$ million in the next decade to continue providing undergraduate training for future scientists. That conclusion appears in a preliminary draft report writ-

Earned doctorates in empirical and life sciences

\begin{tabular}{lc}
\hline$\quad$ Institution & Percentage \\
Cal Tech & 37.5 \\
Harvey Mudd* & 37.2 \\
MIT & 18.6 \\
Reed* & 12.8 \\
UC San Diego & 10.8 \\
Swarthmore* & 8.2 \\
Haverford* & 7.5 \\
Carnegie Mellon & 6.4 \\
Wabash* & 6.4 \\
Chicago & 6.2
\end{tabular}

Percentage of graduates earning doctora degrees comparing 50 liberal arts colleges with 20 top rated universities, Starred institutions are among 50 liberal arts colleges.

ten by Sam Carrier and David Davis-Van Atta of Oberlin College, presented last month at a conference on the future of science at liberal arts colleges.

The report is the second in a series assessing the role of small colleges as a training ground for scientists. The 1985 report showed that liberal arts colleges were relatively immune to a nationwide decline in the numbers of new students expressing an interest in majoring in a science discipline. Nearly 30 per cent of entering freshmen at the 50 liberal arts colleges included in the report said they were planning to major in science, compared with a national average of only 5 per cent. Women continue to represent a rising percentage of baccalaureate degrees in the sciences. More than 40 per cent of all undergraduate degrees for women in the 50 colleges were in the sciences.

The report attributes a large part of this strong showing to the close link between teaching and faculty research on the small campuses. Measures of academic distinction show graduates of the liberal arts colleges fare well when compared with graduates from larger universities. Carrier says the importance of liberal arts colleges is the quality of the students they produce as much as the quantity.

A problem for the smaller colleges is a stratification of faculty. At present their science faculties are overwhelmingly male (89 per cent), nearly all white (96 per cent), mostly in temured positions (69 per cent) and relatively old (average age 44 30 or older than 55 .

\section{Chernobyl} incorporated into the design. years). The age distribution is skewed, with relatively few faculty younger than

The 1986 report identifies the investments needed to maintain a strong position. Assuming a 1.1 per cent growth in faculty positions will be needed in the next decade, paying for these positions will cost an estimated $\$ 369$ million. To continue to attract a strong faculty, $\$ 532$ million will be needed to support faculty research, and an additional $\$ 150$ million for new laboratories and classrooms.

Appropriate ways of increasing investment in undergraduate science education have been a hot topic at the National

Science Foundation (NSF) recently. A National Science Board task committee chaired by Homer Neal (see Nature 320, $479 ; 1986$ ) called on NSF to increase its support for undergraduate education to $\$ 100$ million annually. But NSF must still decide how to implement the Neal report recommendations, and must then win approval for new expenditures from the White House Office of Management and Budget and the Congress.

Carrier believes that the liberal arts colleges would fare well in competition for new NSF grants, but he expects a mix of federal, corporate and foundation support will be necessary to achieve financial goals. A third report to be produced by next summer will assess the issue of where the money should come from.

Joseph Palca

\title{
Inquest continues on nuclear power
}

THE Soviet Union is to introduce structural improvements into the design of its nuclear power stations, according to Viktor Sidorenko, deputy chairman of the USSR State Committee for the Supervision of Safe Working Practices in the Nuclear Power Industry. But the type of improvement will be determined only after a detailed study has been made of the causes of the Chernobyl disaster.

In a statement released through the TASS news agency last week, Sidorenko said that his committee had been repeatedly asked, during the past few weeks, whether every reactor should have a dome-type containment building, which would prevent the emission of radioactive material into the external environment. Before Chernobyl, the Soviet stance had been that such containment buildings were unnecessary, and were merely a way for capitalist constructors to increase their profits. Sidorenko, however, took a slightly different line: that containment buildings are simply an alternative approach to safety, and that the Soviet system of modular "strong boxes", as used at Chernobyl, is a valid equivalent. It would be difficult to say at this stage, Sidorenko stated, whether a containment building would have reduced the scale of the Chernobyl emission.

Whether the two approaches are truly equivalent is a moot point. As a recent open letter to the International Atomic Energy Agency (IAEA) from an unofficial team of Polish scientists stressed, Soviet reactors have only two levels of containment, not as in the West, three. The more cautious purchasers of Soviet VVER reactors - Finns, Hungarians and Poles - have therefore insisted on a Western-style containment building being

Certainly the "modular strong-box" approach failed to work for the RBMK reactor at Chernobyl, although, as Boris Semenov, deputy chairman of the USSR State Committee for Nuclear Energy, said in an interview with the Moscow Literaturnaya Gazeta in June, the design was intended to be sufficient to stop the leakage of radioactive material from the worst possible accident that could be foreseen: an instantaneous transverse rupture of the pressure header of the main circulation pumps.

One of the tasks of the government commission set up immediately after the accident is to determine and report on its cause or causes. Its other, and even more pressing duty, is to "eliminate the consequences" of the disaster. Since this is proving an extremely complex task, the report, which since the end of May has been promised "shortly", is not yet complete. (The arduous nature of the twofold task has, so far, worn out at least four, and possibly five, commission chairmen, all deputy premiers of the USSR.) Even without the official findings, and in spite of reports of faulty construction at Chernobyl, which appeared in the Ukrainian press before the accident, at least one Soviet official is quite sure that neither the design nor the construction of the Chernobyl plant was to blame.

Two days after Sidorenko's statement to TASS, Aleksei Makhukhin, First Deputy Minister of Power and Electrification, told the other official Soviet news agency, Novosti, that the accident seems to have been due to "a coincidence of several highly improbable and hence unforeseeable failures". Nevertheless, he admitted, although neither design nor construction was at fault, additional measures would be introduced to ensure greater safety of nuclear power engineering.

Vera Rich 